\title{
Europe embraces the fast breeder reactor
}

\section{The International Nuclear Fuel Cycle Evaluation has given a boost to the fast breeder reactor. But while the US is rejecting the breeder, others are embracing it, writes Robert Walgate}

FRANCE'S fast breeder programme is already many years ahead of any other nation's. Last week Electricité de France announced an order for a further two fast reactors of $1500 \mathrm{MW}$ each to supplement Super-Phenix, a commercial demonstration reactor due to produce electricity in 1983, so confirming the French lead.

But while France may be ahead in practice, other European countries are with her in spirit. Last month the Council of Foreign ministers of the nine-nation European Community drafted a resolution urging member states which have fast breeder programmes to "get on with them", and offering "appropriate" EEC support. Already, Euratom loans are available to countries developing fast breeders.

Moreover, the Assembly of the Council of Europe, a loose association of 18 European states, recently adopted a resolution that "current programmes in Europe for the development of fast breeder technology to the point of commercialsized demonstration plants should be continued".

Dr Walter Marshall, Deputy Chairman of the United Kingdom Atomic Energy Authority, and a prominent member of INFCE, argued last week that countries with an advanced nuclear programme, such as those of Europe, should concentrate on fast breeders, leaving

- Maurice Bazin reports from Rio de Janeiro on the Brazilian response to INFCE.

The response is one of relief and diplomatic excitement. The controversial multi-billion dollar nuclear agreement with West Germany, signed in 1975, which envisages the construction of up to eight plants of 1,200 MW by 1990, accompanied by uranium enrichment and fuel reprocessing facilities, remains unaffected.

"There was a consensus at the meeting that its conclusions will have no moratorium effect on our nuclear programme and will not serve as a pretext for modifying existing treaties" declared Hervasio de Carvalho, director of the National Commission for Nuclear Energy (CNEN) who attended the INFCE sessions. "The results will be distributed among all countries without discrimination, but no country will be forced to take special measures as a result of the technical exercises carried out by INFCE." thermal reactors to other countries.

Dr Marshall, who once described INFCE as "an exercise in proliferation" because it would help communicate sensitive technologies from the most to the least nuclear of its 66 participants, said that such a regime "would not guarantee the non-proliferation of nuclear weapons . . . but it does give the maximum opportunity to governments ... to secure the most proliferation-resistant regime possible."

Last week the UK House of Lords debated the fast breeder issue, prompted by the Council of Europe resolution. Viscount Thurso, whose fief includes the Dounreay prototype fast reactor, compared progress.

"Our own PFR deliberately contains fuel elements of commercial size such as will be used in a commercial demonstration fast reactor, and employs boiler and coolant pump designs of a commercial sort which will only have to be scaled up slightly for CDFR. Super-Phénix will have to use fuel elements and boilers of designs hitherto untested in practice, and will in consequence have a fairly large question mark hanging over it."

In the US "EBRII is still running but FFTF is doing criticality tests only and work on CFBR has stopped . . . The state of progress in Russia indicates that BN600 is not yet critical and may not be operational until 1983 and although they are preparing to start on $\mathrm{BN} 1600$, they have a long way to go with its design, especially in the field of fuel technology."

In Japan "where they very much need atomic energy . . . they are very far behind schedule. Monju, scheduled for operation in 1986, is not yet in building and it is only the equivalent of our PFR.

"In Germany, the KNK11, is only a converted thermal reactor and SNR300 is delayed by legislation; SNR2 is only a gleam in their eye. In France alone is progress being maintained, although in my view they are behind us is fuel element and boiler design and have an unproved fuel cycle."

Britain should thus move rapidly to the promised public enquiry on the CDFR, argued the Viscount, and in this he was supported by most speakers. Only two strong voices were raised against - those of Lord Avebury, an engineer and a Liberal, and Lord Bowden, an exSecretary of State for Education and Science.

Lord Avebury welcomed the debate not because of the immediate need for the fast breeder but "as a warning of the powerful onslaught which is to be expected from the nuclear lobby if, and when, the government initiate the public inquiry".

"I think that the adoption of breeder technology, plus the reprocessing of the spent fuel from thermal reactors, which of course involves the separation of plutonium, would mean that by the middle of the next century . . . there would be 25 or 30 nations with at least a primitive weapons capability."

And Lord Bowden questioned the economics of the reactors. "No-one can be found to deny that a fast breeder reactor will cost very much more than a conventional type. The ratio has been variously estimated at five times. The Germans have found that their own estimated cost has escalated ten times since they first started on the work."

The price of uranium must rise dramatically, said Lord Avebury, if the fast reactor was to be economic - perhaps from its present level of $\$ 40$ per pound to $\$ 218$ per pound, according to a study prepared by the US Arms Control and Disarmament Agency. But at these prices, argued Lord Bowden, there would be an increase in the size of economic uranium by a substantial factor, perhaps sufficient to equal the maximum breeding factor attainable in a fast reactor.

This breeding factor (the energy obtainable per pound of uranium in a fast breeder as compared with a thermal reactor cycle) "will be less than a dozen times in practice on any system which has so far been proposed and worked out in detail" and not the theoretical factor of 70 commonly quoted. "The Americans are very shrewd in their assessment of economic potential" said Lord Bowden "and they have decided there is no case for developing the fast breeder for several years to come . . . So I am afraid that if we go ahead with the fast breeder in Europe we shall repeat almost precisely the story of Concorde: it will be a technical trimph and an economic catastrophe."

Lord Bowden urged the government instead to consider the Canadian CANDU reactors "which get three of four times as much power per tonne of uranium" as pressurised water or advanced gas-cooled reactors as a way of conserving uranium. "The amount of power we shall in practice get from fast breeders is nowhere near the theoretical amount postulated. It will almost certainly take at least 20 years before the fast breeder can double the amount of fissile material it has to start with. It will take several tonnes of plutonium to start off a fast breeder and, when it has been started, the plutonium and the blanket have to be taken out and reprocessed chemically many, many times."

"I beg the government" said Lord Bowden "to consider this as an alternative". 